ISSN electrónico: 1885-5210

DOI: http://dx.doi.org/10.14201/rmc20201627785

\title{
LA MATERNIDAD SUBROGADA A TRAVÉS DE TRES PELÍCULAS
}

\section{Surrogate maternity through three commercial films}

\author{
M Teresa ICART ISERN ${ }^{1}$; Montserrat DÍAZ MEMBRIVES²; M Carme ICART ISERN ${ }^{3}$ \\ ${ }^{1}$ Facultad de Medicina y Ciencias de la Salud. Escuela de Enfermería (Universidad de Barcelona). España. ${ }^{2}$ Hospital \\ Duran i Reynals/HUB| Institut de Diagnòstic per la Imatge. Facultad de Medicina y Ciencias de la Salud. Escuela \\ de Enfermería (Universidad de Barcelona). España. ${ }^{3}$ Área Básica de Salud "Sant Josep" (Instituto Catalán de la \\ Salud). Facultad de Medicina y Ciencias de la Salud. Escuela de Enfermería (Universidad de Barcelona). España. \\ e-mail: mticart@ub.edu
}

Fecha de recepción: 26 de julio de 2019

Fecha de aceptación: 10 de septiembre de 2019

Fecha del Avance On-Line: 3 de marzo de 2020

Fecha de publicación: 1 de junio de 2020

\section{Resumen}

La maternidad subrogada, la gestación por sustitución o los vientres de alquiler, entre otros, son algunos de los términos empleados en debates de creciente actualidad y cuyo primer caso documentado tuvo lugar en Michigan (EEUU) en 1976. En el presente artículo se parte de diferentes conceptos asociados a la maternidad subrogada (MS), se analizan desde diferentes perspectivas las películas Femmes ou maîtresses (2001) de J.M. Pallardy, Como los demás (2008) de V. Garent y Melody (2014) de B. Bellefroid y, finalmente, se considera la relación entre la maternidad subrogada y la pobreza femenina.

Palabras clave: maternidad subrogada; "vientres de alquiler"; gestación por sustitución; cine.

\section{Abstract}

Surrogate motherhood, pregnancy by substitution or the surrogacy, among others, are some of the terms used in discussions of this topic and which first documented case took place in Michigan (USA) in 1976. This article is based on different concepts related to surrogate motherhood (SM), three films are analyzed from different point of view, Femmes ou maitresses (2001) by J.M. Pallardy, Comme les autres (2008) by V. Garent and Melody (2014), by B. Bellefroid, and eventually, the relationship between female poverty and surrogate motherhood is considered.

Key words: surrogate motherhood; hired womb; surrogate pregnancy; movies. 


\section{LA MATERNIDAD SUBROGADA A TRAVÉS DE TRES PELIICULAS \\ M. TERESA ICART ISERN; MONTSERRAT DÍAZ MEMBRIVES; M. CARME ICART ISERN}

La maternidad o gestación subrogada: un proceso para otros/as

En un sentido amplio los términos gestación y maternidad asociados a los de sustitución o subrogación se refieren al hecho de que una mujer se presta a gestar un niño o niña para entregarlo/ la a quien/es se lo han encargado y que a partir de entonces asumirá/n su paternidad o maternidad. Se trata de un acuerdo o contrato entre dos partes: la mujer gestante que renuncia a los derechos de filiación y la persona o pareja comitente, subrogante, aspirante o intencional que ha hecho el encargo ${ }^{1,2}$.

La maternidad subrogada (MS) contempla una perspectiva médica (reproducción asistida) y una perspectiva legal. Respecto a la reproducción asistida puede ser por inseminación artificial (se fecunda un óvulo de la mujer gestante por inyección seminal en su vagina) o reproducción in vitro (se fecundan varios óvulos dentro de una probeta, se selecciona uno o varios embriones viables y se introducen en el útero de la mujer previamente estimulado para que acoja el embrión).

Por su parte, los padres o madres comitentes o subrogantes pueden, o no, guardar relación genética con el niño/a. La pareja comitente puede estar formada por la propietaria del óvulo y su pareja o el propietario del semen y su pareja, pero también pueden obtenerse los gametos de terceras personas mediante donación o compra.

Desde una perspectiva legal y ética, la MS es un tema controvertido por su carácter disruptivo respecto al modo en que tradicionalmente se ha entendido la relación entre maternidad y filiación. En ese sentido, la legislación civil establece que la filiación se determina por el parto, es decir, la mujer que dé a luz es la madre legal. La MS implica la cesión del bebé gestado a otra u otras personas que lo filiarán en el Registro Civil o sea que se cede a los subrogantes el derecho de considerar al bebé como legalmente propio ${ }^{3}$.

Es preciso clarificar el término subrogada, según la RAE significa "sustituir o poner a alguien o algo en lugar de otra persona". En este sentido, la sustitución en la gestación sería un eufemismo, porque gestar, al igual que respirar, no se puede hacer por otra persona ${ }^{4}$. Es evidente que la gestación engloba aspectos fisiológicos y psicológicos fundamentales; entre los primeros destaca la hormonación, el embarazo, el parto y el postparto y entre los segundos, cuentan los vínculos afectivos entre la gestante y el feto ${ }^{5}$. Se debe tener en cuenta que en el embarazo se produce una elevada interacción entre la gestante y el feto, pudiéndose detectar genes fetales en sangre materna después del embarazo, también la configuración epigenética del feto cambia según el entorno uterino en el que se desarrolla ${ }^{4,6}$.

En un sentido estricto la expresión "vientre de alquiler" se reservaría al caso de una mujer que presta su útero para gestar el óvulo fecundado (embrión) de otra mujer, por lo tanto, la gestante no guardaría relación genética con el futuro/a niño/a. Para los que se oponen a la MS, sería más preciso hablar de "madre de alquiler", para referirse a una transacción o compraventa entre la gestante y los comitentes ${ }^{7}$. Sin embargo, esta expresión se considera ofensiva para las mujeres que gestan de manera altruista.

Una cuestión polémica es el propio significado del término madre, ¿quién sería la madre (la genética, la gestante o la contractual) o el padre (el genético, la pareja de la gestante o el contractual)? A la polémica se añade la valoración de los derechos del recién nacido, que no siendo propiedad de los padres se considera un sujeto de protección ${ }^{8}$.

\section{Situación de la maternidad subrogada en el mundo}

Las cifras de la MS a nivel mundial o nacional varían según las fuentes utilizadas por las instituciones u organismos. La fiabilidad de estas cifras es cuestionable ya que algunas adopciones internacionales encubren casos de MS. Según Life Bridge $^{9}$ la cifra de los niños/as nacidos gracias a un programa de MS ha pasado de 192 a 33.644 entre 2014 y 2018, lo cual supone de 1,35 a 2,35 


\section{LA MATERNIDAD SUBROGADA A TRAVÉS DE TRES PELÍCULAS \\ M. TERESA ICART ISERN; MONTSERRAT DÍAZ MEMBRIVES; M. CARME ICART ISERN}

respectivamente por cada millón de habitantes en el mundo.

El Ministerio de Asuntos Exteriores del Gobierno de España ${ }^{10}$ cifró en 979, los hijos inscritos entre 2010 y 2016 por gestación subrogada en oficinas consulares y misiones diplomáticas españolas situadas en doce países, entre ellos Canadá, EEUU, India, Nepal, México, etc. Cabe destacar que la MS es una práctica no legalizada en España y respecto a la cual el Comité de Bioética del Ministerio de Sanidad ha pedido la prohibición a nivel internacional por considerar que los contratos que avalaban dicha práctica atentan contra la dignidad de la mujer y del recién nacido ${ }^{3,11,12}$.

\section{La maternidad subrogada en el cine}

Las películas que tratan, con enfoques diversos, algún aspecto relacionado con la MS son múltiples (tabla 1) de ellas se comentan tres títulos producidos en 2001, 2008 y 2014.

Tabla 1. Títulos y características de películas sobre maternidad subrogada

\begin{tabular}{|c|c|c|c|c|}
\hline Título & Año & Director & País & Causa de la subrogación \\
\hline Un especie de familia & 2017 & Diego Lerman & Argentina & $\begin{array}{l}\text { Mujer que ha abortado } \\
\text { (esterilidad) }\end{array}$ \\
\hline Diane a les épaules & 2017 & Fabien Gorgeart & Francia & Pareja gay \\
\hline Shelley & 2016 & Ali Abbassi & Dinamarca/Suecia & Esterilidad femenina \\
\hline Obsesión fatal & 2016 & Jon Cassar & Estados Unidos & Varón gay \\
\hline Nasty baby & 2015 & Sebastian Silva & Gran Bretaña & Varón gay \\
\hline Melody & 2014 & Bernard Bellefroid & Bélgica/Luxemburgo/Francia & Esterilidad femenina \\
\hline The sessions & 2012 & Ben Lewin & Gran Bretaña & Varón gay \\
\hline $\begin{array}{l}\text { Ende der Schonzeit } \\
\text { (Closed Season) }\end{array}$ & 2012 & $\begin{array}{l}\text { Franziska } \\
\text { Schlotterer }\end{array}$ & Alemania/Israel & Esterilidad masculina \\
\hline Thy Womb & 2012 & Brillante Mendoza & Filipinas & Esterilidad femenina \\
\hline Life express & 2010 & Anup Das & India & Ejecutiva que no desea gestar \\
\hline Baby mama & 2008 & Michael McCullers & Estados Unidos & Esterilidad femenina \\
\hline Como los demás & 2008 & Vincent Garenq & Francia & $\begin{array}{l}\text { Pareja gay (Esterilidad } \\
\text { masculina) }\end{array}$ \\
\hline Skagerrak & 2003 & $\begin{array}{l}\text { Soren Kragh- } \\
\text { Jacobsen }\end{array}$ & $\begin{array}{l}\text { Dinamarca/ Suecia/ Gran } \\
\text { Bretaña/ España/Alemania/ } \\
\text { Francia/ Suiza }\end{array}$ & Esterilidad femenina \\
\hline $\begin{array}{l}\text { Femmes ou maitresses } \\
\text { / The donor }\end{array}$ & 2001 & $\begin{array}{l}\text { Jean Marie } \\
\text { Pallardy }\end{array}$ & Estados Unidos & Esterilidad femenina \\
\hline Chutney Popcorn & 1999 & Nisha Ganatra & Estados Unidos & Esterilidad femenina \\
\hline A la luz del fuego & 1997 & William Nicholson & Gran Bretaña & Varón soltero \\
\hline Más allá del odio & 1996 & René Eram & Estados Unidos & Pareja estéril \\
\hline El cuento de la doncella & 1990 & Volker Schlöndorff & Alemania & Esterilidad femenina \\
\hline Madre alquilada & 1987 & Kwon-taek Im & Corea del Sur & Esterilidad femenina \\
\hline Showa onnamichi & 1972 & Chûsei Sone & Japón & Esterilidad femenina \\
\hline Un bebé para mi esposa & 1970 & James Bridges & Estados Unidos & Esterilidad femenina \\
\hline Haragashionna & 1968 & Kôji Wakamatsu & Japón & Esterilidad femenina \\
\hline
\end{tabular}

Rev. Med. Cine. 2020; 16(2), 79-89 Ediciones Universidad de Salamanca / @®® J. Med. Mov., 2020; 16 (2), $79-89$ 


\section{LA MATERNIDAD SUBROGADA A TRAVÉS DE TRES PELÍCULAS \\ M. TERESA ICART ISERN; MONTSERRAT DÍAZ MEMBRIVES; M. CARME ICART ISERN}

Un "vientre de alquiler" que acaba en amor: Femmes ou maîtresses

Título original: The donor.

Otros títulos: Femmes ou maîtresses.

País: Estados Unidos.

Año: 2001.

Director: Jean-Marie Pallardy.

Música: Nicolas Skorsky.

Montaje: Eduard Pallardy.

Guion: Neal H. Dobrofsky, Tippi Dobrofsky.

Intérpretes: David Carradine (Mike Riordan), Pierre Dulat (Mathieu/Matt Riordan), Florence Guérin (Sylvia), Marina Anderon (Françoise Riordan), Karen Black (Mrs. Springle), James Handy (John Springle).

Color: color.

Duración: 95 minutos.

Género: comedia, drama

Idioma original: inglés.

Productoras: Sedat Akdemir, Bernard Bergman, Kathleen Lohr.

Sinopsis: Matt y Françoise desean tener descendencia, pero ella es estéril. Su situación económica les permite contratar a una madre de alquiler. Matt siente curiosidad por la mujer que mediante inseminación artificial está gestando un hijo para la pareja y decide ir a su encuentro. En una isla turca descubre a Katy quien a cambio de dinero ha aceptado gestar un hijo y con la que acabará estableciendo una relación especial. Enlace: https://www.imdb.com/title/tt0251054

\section{Tráiler}

Femmes ou maîtresses plantea el deseo de descendencia de un matrimonio americano de clase alta; Matt es ingeniero y está casado con Françoise, la hija de un empresario de la construcción. La joven heredera se muestra caprichosa y displicente, hacia las muestras de afecto de Matt, obsesionado con ser padre. Cuando las repetidas consultas con prestigiosos ginecólogos confirman la esterilidad de Françoise, será el hermano de Matt, un pintor bohemio, quien aportará la solución a través de una agencia de intermediación que conecta a potenciales gestantes con parejas deseosas de descendencia.

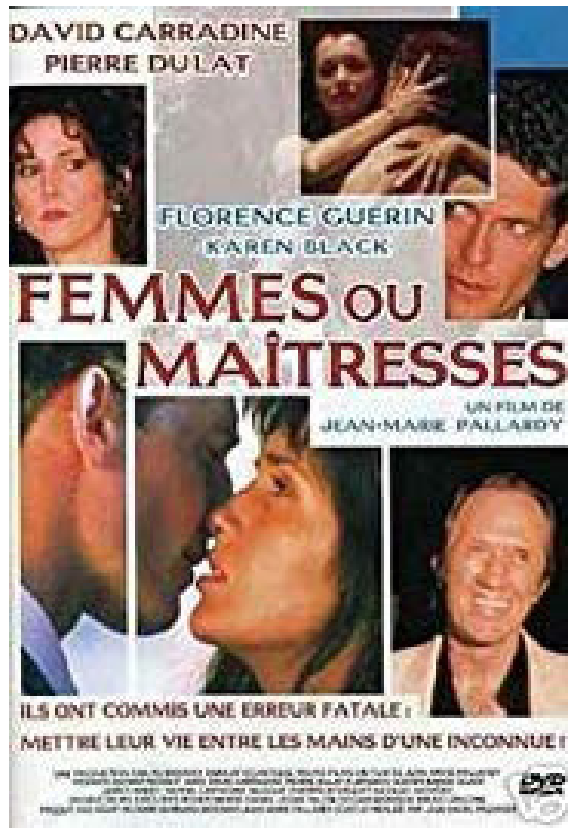

Carátula francesa de The donor.

La visita a un facultativo sirve para informar a la pareja sobre los aspectos legales y médicos de la MS. Para sortear los problemas legales se articula una estrategia según la cual tan pronto la madre de alquiler quede embarazada, Françoise (la comitente) simulará un embarazo que trascurrirá en el extranjero y al regreso del cual, la pareja aparecerá con el bebé gestado por la madre de alquiler.

El procedimiento trascurre como se había planificado, pero Matt no deja de preguntarse cómo es la madre de su hijo biológico. Cuando averigua el paradero de la gestante, situado en una isla turca, vuela a su encuentro. Allí conoce a Katy una mujer saludable de mediana edad que, con la ayuda de unos amigos, está reparando un barco con el que piensa partir hacia otro lugar donde iniciar una vida mejor para ella y su hija; 


\section{LA MATERNIDAD SUBROGADA A TRAVÉS DE TRES PELÍCULAS \\ M. TERESA ICART ISERN; MONTSERRAT DÍAZ MEMBRIVES; M. CARME ICART ISERN}

Matt, que oculta el verdadero motivo de su visita, se presenta aportando sus conocimientos como ingeniero. Regresa a la isla en dos ocasiones, pero en ninguna de ellas informa a Katy que él es el padre biológico del hijo que ella está gestando, tampoco ella le comunica su situación. Katy decide abortar justo antes de la llegada de Matt (Foto 1); tras el reencuentro, ambos se sienten libres para iniciar una vida en común.

En Femmes ou maîtresses, la gestante quiere obtener una compensación económica por su embarazo; ignora quién es el donante del esperma con el que fue inseminada. Es evidente que antes del embarazo ha renunciado a cualquier derecho sobre el futuro bebé.

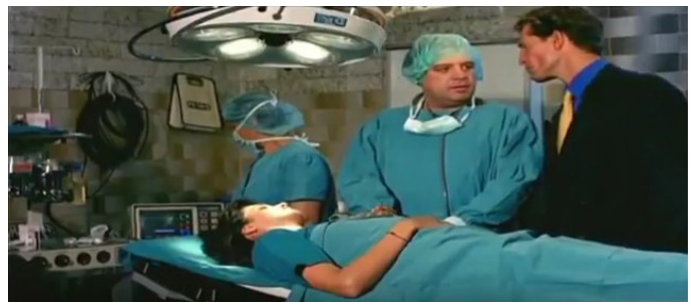

Foto 1. Katy que acaba de abortar junto a Matt.

En cuanto a la dotación genética, el óvulo procede de la gestante y el semen del comitente que forma una pareja con Françoise que es estéril como se demuestra tras sucesivos intentos de quedar embarazada. Los comitentes y la gestante viven en países diferentes, los unos en un país rico y la otra en un país pobre donde cuenta con amigos que le apoyan en su proyecto.

Existe una relación comercial entre los comitentes y la gestante, a ambas partes las ha puesto en contacto una agencia que promueve la reproducción asistida mediante inseminación artificial, no se describe si ha mediado una estimulación ovárica. Sí sabemos que la gestante es una mujer libre y que es la primera vez que se somete a esta práctica y que ya ha sido madre de una niña sana con la que convive.

Desde una perspectiva social y ética, Femmes ou maîtresses, se posiciona a favor de la MS.
Ambas partes actúan con libertad, aunque se trata de una transacción entre quien ostenta el poder económico y una mujer pobre. El film es un buen ejemplo de la feminización de la pobreza ${ }^{13,14}$. No obstante, en Femmes ou maîtresses, Katy no se siente explotada, percibe su gestación como un trabajo. La perspectiva de iniciar una relación con Matt precipita su decisión de abortar y de devolver el dinero que ha recibido a cuenta de la gestación.

Una gestación subrogada altruista y por amor: Comme les autres

Título: Como los demás.

Título original: Comme les autres.

País: Francia.

Año: 2008.

Director: Vincent Garenq.

Música: Robert Burke; Loïc Dury; Laurent Levesque.

Fotografía: Jean-Claude Larrieu.

Montaje: Dorian Rigal-Ansous.

Guion: Vincent Garenq.

Intérpretes: Lambert Wilson (Manu), Pilar López de Ayala (Josefina/Fina), Pascal Elbé (Philippe), Anne Brochet (Cathy).

Color: color.

Duración: 89 minutos.

Género: comedia; drama.

Productora: Christophe Rossignon.

Sinopsis: Manu y Philippe forman una feliz pareja de gays, pero les separa el deseo no compartido de paternidad. Manu inicia una adopción monoparental y le pide a Philippe que abandone el piso que comparten porque la legislación francesa es contraria a la adopción homoparental. Cuando fracasa su intento de adopción, decide pedirle a Fina, una joven argentina, que se quede embarazada y le ceda el bebé, a cambio, le ofrece un matrimonio de conveniencia que le sirva para legalizar su situación.

Enlaces: https://www.imdb.com/title/tt1093352/ https://www.filmaffinity.com/es/film128256.html 


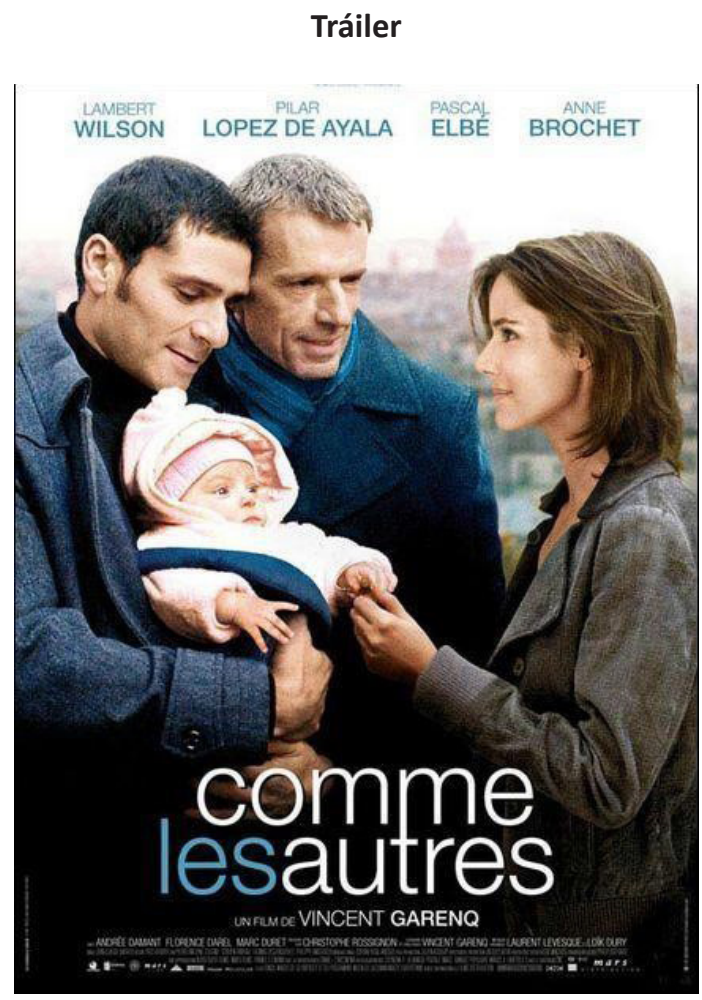

Cartel español de Como los demás.

Manu (pediatra) y Philippe (abogado) forman una pareja estable de cuarentones adinerados residente en Paris, pero su discrepancia respecto al deseo de paternidad les llevará a una separación amistosa. En solitario Manu inicia un proceso de adopción haciéndose pasar por un soltero heterosexual, pero cuando se descubre que es gay su solicitud es rechazada.

Casualmente, a raíz de un accidente automovilístico sin consecuencias, conoce a Josefina (Fina), una joven argentina a punto de acabar su beca como estudiante de diseño. Tras un breve encuentro al que le sigue una cena, Manu propone a la joven un matrimonio de conveniencia, gracias al cual ella podría regularizar su situación. a cambio Fina gestaría un hijo mediante inseminación artificial, propuesta que la joven rechaza de inmediato.
Entonces Manu inicia una serie de entrevistas con diferentes mujeres, entre ellas algunas parejas de lesbianas, con la intención de encontrar una madre de alquiler. Cuando Fina es detenida por conducir sin seguro, contacta con Manu que paga la fianza y la aloja en su casa. El trato amable y cariñoso de Manu hace que la joven agradecida acabe accediendo a gestar un hijo para él (Foto 2). Pero cuando una analítica revela que Manu es estéril (azoospermia), este decide pedir a Philippe, su ex pareja, que sea el donante.

Cuando Fina queda embarazada por inseminación artificial tiene lugar una gran boda. Entretanto la joven se ha enamorado de Manu quien reinicia su relación con Philippe. Cuando ella le recrimina sus preferencias sexuales, Manu reconoce el error y le propone abortar, a lo que ella responde abandonándole.

El embarazo prosigue su curso y llegado el momento del parto, la pareja de gais que ha retomado su relación acompaña a Josefina que da a luz a una niña. La joven admite no poder cuidar de la bebé, afirma querer recuperar su vida y entre lágrimas, a la salida de la clínica, entrega la recién nacida a Manu, dando por concluida toda relación con la pareja gay. En la secuencia final, reaparece Fina sonriente ante Manu y Philippe que pasean a su hija por una calle de Paris.

Como los demás parte del diagnóstico de azoospermia y presenta la inseminación artificial como recurso ante un caso de esterilidad de un varón gay que desea ser padre siendo su pareja el donante del esperma. El film muestra el seguimiento del desarrollo del feto (ecografía) y el mismo trabajo del parto (fase de expulsión).

Además, como Manu es pediatra se le ve atendiendo a varios niños que presentan diferentes problemas (otitis, asma, fiebre, etc.), también tranquiliza a una madre preocupada por el desarrollo de su hijo y a la que explica que el crecimiento del niño es normal y acorde a la curva pondoestatural (Foto 3). 


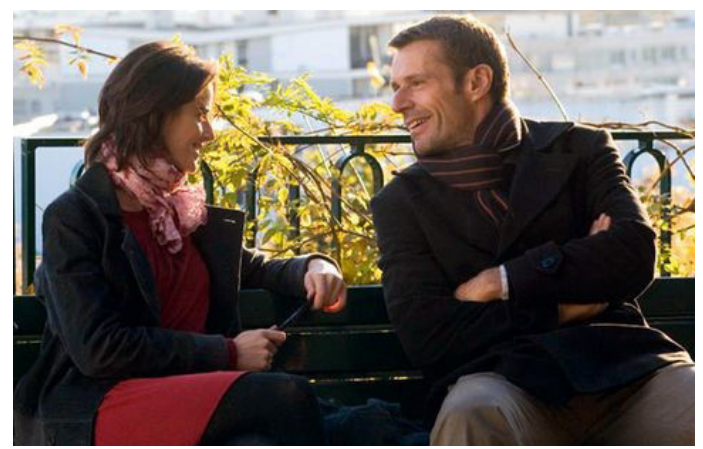

Foto 2. Manu (el gay que desea ser padre) y Fina (quien será gestante por altruismo).

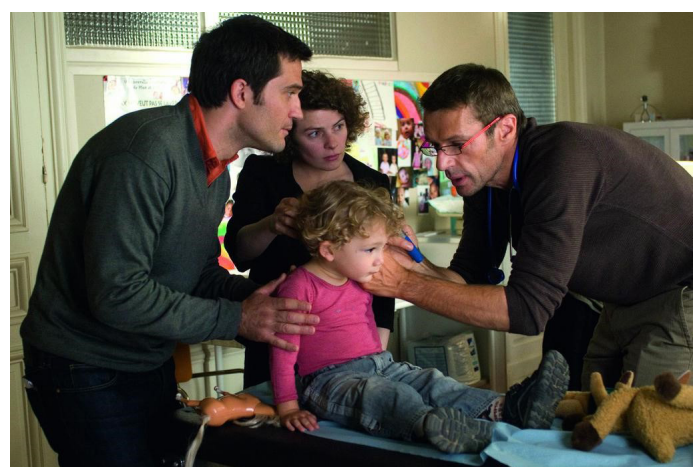

Foto 3. Manu en su labor como pediatra.

En Como los demás, la gestante actúa por altruismo, no existe un vínculo familiar con los padres comitentes (una pareja de varones homosexuales). Ni antes, ni durante el embarazo se acuerda la renuncia de la gestante al recién nacido, pero al que sí renuncia después del parto. El óvulo es de la gestante y el esperma pertenece a uno de los padres comitentes. Se recurre a la subrogación por imposibilidad biológica de los comitentes (pareja de varones). Estos y la gestante residen en Paris, siendo ella una estudiante sin recursos que actúa con total libertad sin que medie relación contractual alguna entre las partes. La gestación se produce por inseminación artificial en una mujer primípara que actúa por altruismo y gratitud ${ }^{15} y$ que antepone su desarrollo profesional ante la carga que supone una maternidad en solitario.
La maternidad de alquiler como un medio para realizar los sueños: Melody

Título original: Melody.

País: Francia.

Año: 2014.

Director: Bernard Bellefroid.

Música: Frédéric Vercheval.

Fotografía: David illiamson.

Montaje: Jean-Luc Simon.

Guion: Bernard Bellefroid, Carine Zimmerlin.

Intérpretes: Rachael Blake (Emily), Lucie Debay

(Melody), Don Gallagher (Gary), Laure Roldan

(Marion), Clive Hayward (Norman), Lana Macanovic (Doctor Sirenko).

Color: color.

Duración: 90 minutos.

Género: drama.

Idioma original: inglés.

Productoras: Brigitte Kerger-Santos, Patrick Quinet y Claude Waringo.

Sinopsis: Melody es una joven francesa que decide convertirse en madre de alquiler a cambio de una suma considerable de dinero que le permita abrir un salón de belleza. Emily es la mujer inglesa que la ha contratado, pertenece a una clase acomodada, y convence a Melody para vivir juntas y así poder controlar todo el proceso del embarazo y parto. En un principio ambas mujeres parecen pertenecer a dos mundos paralelos, sin embargo, entre ambas se teje una relación especial.

Premios: Festival de Montreal (2014): Mejor actriz (Rachael Blake y Lucie Debay).

Enlaces: https://www.imdb.com/title/tt2296857/ https://www.filmaffinity.com/es/film224667.html

\section{Tráiler}

Melody aborda el drama de una joven cuya precariedad económica le impide realizar su sueño: abrir un salón de belleza. Melody vive en un barrio obrero donde peina clientas a domicilio y con las que comparte afecto, complicidades y carencias
Rev. Med. Cine. 2020; 16(2), 79-89

Ediciones Universidad de Salamanca /

[ 85 ] 
(Foto 4). Ante la imposibilidad de reunir el dinero para cumplir su proyecto, decide actuar como madre de alquiler. Así conoce a Emily, una dama inglesa de clase alta, a la que un cáncer y su posterior tratamiento truncó su deseo de ser madre.

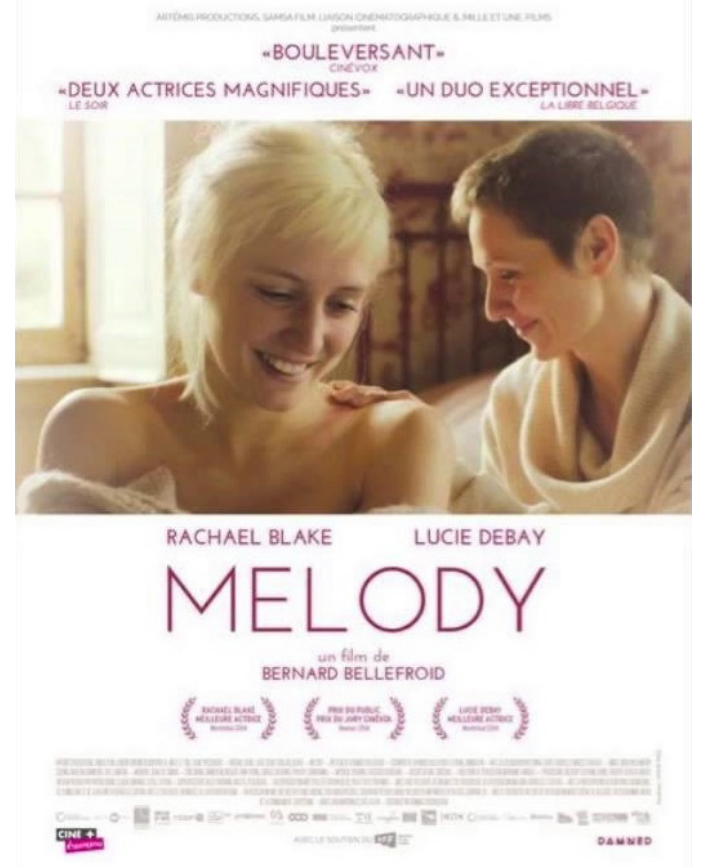

Cartel francés de Melody.

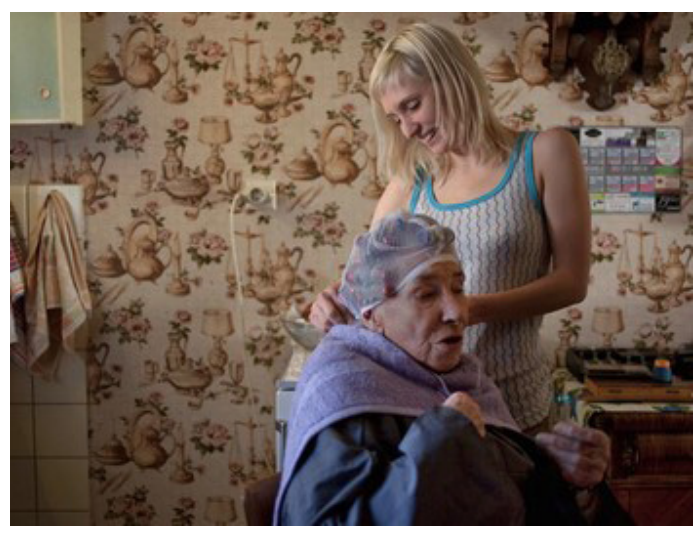

Foto 4. Melody en el domicilio de una clienta.
Emily planifica la fecundación in vitro de Melody a partir de óvulos congelados procedentes de la propia Emily. También organiza la estancia de la joven durante el embarazo y su parto en Ucrania. Pero durante el embarazo Melody empieza a dudar sobre su deseo de renunciar al bebé. $A$ su vez Emily revela su enfermedad y las carencias que se esconden tras su aparente dureza (Foto 5).

El film contrapone los deseos de ambas mujeres: escapar de la pobreza, por parte de Melody y realizarse como madre, por parte de Emily ${ }^{16,17}$. Finalmente el cáncer recidiva y Emily muerte. Melody acaba haciéndose cargo del bebé, en clara contraposición al abandono del que fue objeto por parte de su madre.

En Melody, la gestante persigue una finalidad lucrativa que le permita iniciar un negocio. No tiene ningún vínculo familiar ni afectivo con la madre comitente. Desde el inicio se acuerda la renuncia a la maternidad, pero a medida que avanza la gestación la joven primípara cuestiona el acuerdo. El óvulo procede de la comitente y el esperma de un desconocido. La subrogación responde a una razón médica (esterilidad de la comitente). El embarazo y parto transcurren en el país de la comitente (Inglaterra) al que se traslada la gestante de origen francés. El film muestra el desarrollo controlado (ecografías) del embarazo.

Melody sirve para plantear el conflicto personal de una mujer casi indigente que prefiere alquilarse como madre en lugar de prostituirse ${ }^{13,14}$. El aislamiento compartido de ambas mujeres les acercará en un encuentro que asemeja al de una madre (Emily) con una hija (Melody) ${ }^{16}$.

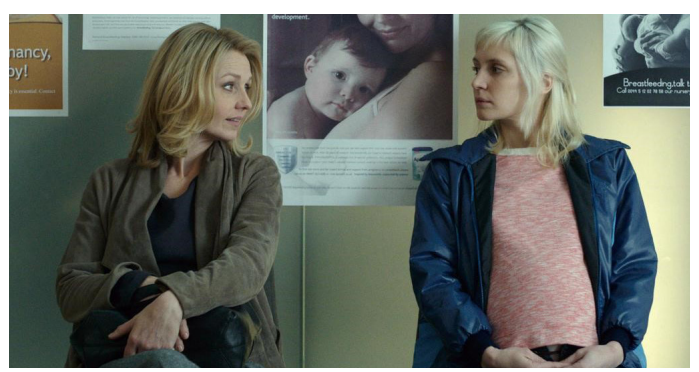

Foto 5. Emily (la subrogante) y Melody (la gestante). 


\section{LA MATERNIDAD SUBROGADA A TRAVÉS DE TRES PELIICULAS \\ M. TERESA ICART ISERN; MONTSERRAT DÍAZ MEMBRIVES; M. CARME ICART ISERN}

La maternidad subrogada como reflejo de la pobreza femenina

Melody al igual que Femmes ou maitresses son ejemplos de la tergiversación del lenguaje que esconde la mercantilización del cuerpo en mujeres pobres, a la vez que oculta el gran negocio de compra-venta de bebés con el que se lucran las agencias de intermediación y algunas clínicas de fertilidad. De este modo se alimenta un sistema patriarcal al servicio de personas pudientes con problemas de fertilidad a expensas de mujeres sin recursos dispuestas a arriesgar su salud física y mental ${ }^{7-19}$.

La situación de las mujeres que actúan como "vientres de alquiler" tiene su máximo exponente en países como India donde el negocio ${ }^{1}$, aportó al país 690 millones de dólares en 2014. La mayoría de gestantes pertenecen a las castas bajas y no son conscientes de los riesgos que conlleva la gestación a la que suelen recurrir coaccionadas tanto por proxenetas como por sus maridos que son quienes firman los contratos. Durante la gestación subrogada algunas mujeres seguirán viviendo en su hogar pero otras serán confinadas en las conocidas como "granjas de mujeres reproductoras" o "baby factory" donde vivirán durante el embarazo hasta proveer de hijos a parejas ricas. Al regresar a sus pueblos es posible que tengan que enfrentarse al desprecio de vecinos y familiares.

Las mujeres son las que pueden sufrir daños irreversibles, las que en un embarazo múltiple deberán abortar los fetos no deseados y que en caso de aborto involuntario no obtendrán ninguna retribución ${ }^{13,14}$. Se trata de un modelo que aplicado a la relación desigual entre gestante pobre y comitentes ricos se podría considerar una forma de neocolonialismo ${ }^{1,20}$. Los costos para los subrogantes oscilan entre 100.000 y $150.000 €$ en la Unión Europea y los EEUU y entre 20.000 y 30.000 en Tailandia, Camboya o India. De estas sumas la gestante recibe un $20 \%$. Esta situación compartida por mujeres de otros países ha dado lugar a la campaña internacional "Stop Subrrogacy
Now" que denuncia la MS equiparándola al tráfico de órganos o de bebés ${ }^{1,21}$.

Melody al igual que títulos como Una especie de familia (2017) de Diego Lerman, son ejemplos de la explotación reproductiva de las mujeres gracias a la que se lucran tanto las agencias de intermediación como algunos médicos y abogados.

En la MS se anulan los derechos por parto y se enfatizan los derechos por vinculación genética (a veces solo jurídica), dando carácter de propiedad tanto a la maternidad como a la paternidad de los comitentes, hecho que deja patente la expresión "que sea mío", una fórmula que justifica la importancia de la carga genética.

Aunque los avances de la ciencia ofrecen nuevas oportunidades para la reproducción no todo lo científicamente posible tiene porque ser lícito y/o ético, por esta razón la ciencia se enfrenta a dilemas jurídicos y éticos a los que se suman algunas corrientes religiosas ${ }^{20-22}$.

\section{Referencias}

1. Emakunde. ¿Gestación subrogada o vientres de alquiler? Informe final [Internet]. Abril de 2018 [citado el 12 de julio 2019].

2. Colaboradores de Wikipedia. Gestación subrogada. Wikipedia, La enciclopedia libre [Internet]. 4 de junio de 2019 [citado el 8 de junio de 2019].

3. Comité de Bioética de España. Informe del Comité de Bioética de España sobre los aspectos éticos y jurídicos de la maternidad subrogada [Internet]. Madrid: 2017 [citado el 19 de julio de 2019].

4. Cátedra de Bioética "Jérôme Lejeune". Informe sobre la llamada "Maternidad por subrogación" [Internet]. 10 de febrero de 2017 [citado el 22 de julio de 2019].

5. Bernaldo L. Las secuelas psicológicas para el bebé en la gestación subrogada. La Vanguardia [Internet]. 8 de junio de 2019 [citado el 22 de julio 2019].

6. Blanco-Morales, P. Una filiación: Tres modalidades de establecimiento. La tensión entre la ley, la biología y el afecto. Millennium DIPr. 2015;(1):1-16. 


\section{LA MATERNIDAD SUBROGADA A TRAVÉS DE TRES PELÍCULAS \\ M. TERESA ICART ISERN; MONTSERRAT DÍAZ MEMBRIVES; M. CARME ICART ISERN}

7. Guerra-Palmero MJ. Contra la llamada gestación subrogada. Derechos humanos y justicia global versus bioética neoliberal. Gaceta Sanitaria. 2017;31(6):535-8.

8. Valdés Díaz, C. del C. La maternidad subrogada y los derechos de los menores nacidos mediante el uso de esas técnicas. Anuario de la Facultad de Derecho. 2014;(31):459-82.

9. LifeBridge. Gestación subrogada en España/Blog. El porcentaje de éxito en programas de maternidad subrogada [Internet]. Marzo de 2010 [citado el 22 de mayo de 2019].

10. Álvarez P. El Gobierno cifra en 979 los hijos inscritos desde 2010 por gestación subrogada [Internet].El País [Internet]. 8 de noviembre de 2017 [citado el 18 de mayo de 2019].

11. Gutiérrez V. Justicia ordena volver a inscribir a los bebés de "vientre subrogado". El País [Internet]. 10 de julio de 2014 [citado el 20 de junio de 2019].

12. Murga J P. La controvertida maternidad subrogada o gestación por sustitución: Status quaestionis en el ordenamiento jurídico español y perspectivas de futuro. En: El mejoramiento humano: avances, investigaciones y reflexiones éticas y políticas Ortega C, Richart A, Páramo V, Ruíz C. [Internet]. Granada: Comares S.L. 2015 [citado el 18 de mayo de 2019]: págs. 607-16.

13. Puleo $\mathrm{AH}$. Nuevas formas de desigualdad en un mundo globalizado. El alquiler de úteros como extractivismo. Revista Europea de Derechos Fundamentales. 2017; (29): 165-84.

14. Balaguer Ma L. Hij@s del mercado. La maternidad subrogada en un Estado Social. Madrid: Cátedra; 2017.

15. Albert MM. La explotación reproductiva de mujeres y el mito de la subrogación altruista: Una mirada global al fenómeno de la gestación por sustitución. Cuad Bioet. 2017; 28(93), 177-97.

16. Caillard G. Melody. Dos madres frente a frente. Cineeuropa [Internet]. 28 de agosto de 2014 [citado el 18 de mayo de 2019].

17. Scheib R. Film Review: "Melody". Variety [Internet]. 5 de septiembre de 2014 [citado el 22 de julio de 2019].

18. Gómez A. Vientres de alquiler. La hermana pequeña de la prostitución. Asturias Laica [Internet]. 13 de marzo de 2017 [citado el 20 de junio de 2019].

19. Ekis Ekman K. El ser y la mercancía. Prostitución, vientres de alquiler y disociación. Barcelona: Ediciones Bellaterra; 2017.

20. Molina C. EI TEDH no da "cheques en blanco" a los padres intencionales es legítimo que el Estado evite la "maternidad subrogada "de facto" " (Comentario a la Sentencia del Tribunal Europeo de Derechos Humanos de 24 de enero de 2017, Paradiso y Campanelli v. Italia, núm. 25358/12). Estudios financieros. Revista de trabajo y seguridad social: comentarios, casos prácticos: recursos humanos [Internet]. 2017. [citado el 20 de junio de 2019]. (408): 121-34.

21. Naciones Unidas. Consejo de Derechos Humanos. Informe de la Relatora Especial sobre la venta y la explotación sexual de niños, incluidos la prostitución infantil, la utilización de niños en la pornografía y demás material que muestre abusos sexuales de niños. A/ $\mathrm{HRC} / 37 / 60$. Consejo de Derechos Humanos. 370 período de sesiones. [Internet]. 26 de febrero al 23 marzo de 2018 [citado el 20 de junio de 2019].

22. Vidal JM. Los obispos condenan la maternidad subrogada: "Un hijo no es un derecho ni un deseo, sino un don". El Mundo [Internet]. 23 de febrero de 2017. [citado el 25 de mayo de 2019]. 
LA MATERNIDAD SUBROGADA A TRAVÉS DE TRES PELÍCULAS

M. TERESA ICART ISERN; MONTSERRAT DÍAZ MEMBRIVES; M. CARME ICART ISERN

\begin{tabular}{|c|c|}
\hline & $\begin{array}{l}\text { María Teresa Icart Isern. Diplomada en Enfermería. Doctora en Medicina y } \\
\text { Cirugía. Máster en S. Pública. Catedrática en Enfermería Comunitaria y S. } \\
\text { Pública en la Escuela de Enfermería (Facultad de Medicina y Ciencias de la } \\
\text { Salud, U. de Barcelona). Coordina las asignaturas de Investigación Clínico- } \\
\text { epidemiológica, Comunicación Científica y Evidencia Científica. Es co-autora } \\
\text { de: Films in Health Sciences Education. Learning through moving images } \\
\text { (Ed:UB, 2012) y de Enfermeras en el cine (Ed: UB, 2015). }\end{array}$ \\
\hline & $\begin{array}{l}\text { Montserrat Díaz Membrives. Diplomada en Enfermería. Doctora en Ciencias } \\
\text { Enfermeras. Es profesora de Enfermería de Salud Pública y Comunitaria } \\
\text { de la Escuela de Enfermería (Facultad de Medicina y Ciencias de la Salud, } \\
\text { U. de Barcelona). Coordinadora de enfermería del Institut de Diagnòstic } \\
\text { per la Imatge (IDI) del Hospital de Bellvitge y del Hospital Duran y Reynals } \\
\text { (Barcelona). }\end{array}$ \\
\hline 7 & $\begin{array}{l}\text { María Carmen Icart Isern. Diplomada en Trabajo Social. Diplomada en Enfer- } \\
\text { mería. Máster Universitario en Liderazgo y Gestión Enfermera. Enfermera de } \\
\text { Atención Primaria en Centro Sant Josep (Institut Català de la Salut). Profesora } \\
\text { Asociada en Escuela de Enfermería (Facultad de Medicina y Ciencias de la } \\
\text { Salud, U. de Barcelona). }\end{array}$ \\
\hline
\end{tabular}


